\title{
Self-centeredness and selflessness: Happiness correlates and mediating psychological processes
}

\author{
Michael Dambrun ${ }^{\text {Corresp. } 1}$ \\ 1 Université Blaise Pascal (Clermont-Ferrand II), Clermont-Ferrand, France \\ Corresponding Author: Michael Dambrun \\ Email address: michael.dambrun@univ-bpclermont.fr
}

The main objective of this research was to test central assumptions from the Selfcenteredness/Selflessness Happiness Model. According to this model, while self-centered psychological functioning induces fluctuating happiness, authentic-durable happiness results from selflessness. Distinct mediating processes are supposed to account for these relationships: afflictive affects (e.g. anger, fear, jealousy, frustration) in the case of the former, and both emotional stability and feelings of harmony in the case of the latter. We tested these hypotheses in two studies based on heterogeneous samples of citizens ( $n=$ 547). Factor analyses revealed that self-centeredness (assessed through egocentrism and materialism) and selflessness (assessed through self-transcendence and connectedness to other) were two distinct psychological constructs. Second, while self-centeredness was positively and significantly related to fluctuating happiness, selflessness was positively and significantly related to authentic-durable happiness. Finally, distinct psychological processes mediated these relationships (study 2). On one hand, the relationship between self-centeredness and fluctuating happiness was fully mediated by afflictive affects. On the other hand, emotional stability and the feeling of being in harmony partially mediated the relation between selflessness and authentic-durable happiness. 


\section{PeerJ}

\section{Manuscript to be reviewed}

1 RUNNING HEAD: Self-Centeredness, Selflessness and Happiness

2

3

4

5

6

7

Self-Centeredness and Selflessness:

8

Happiness Correlates and Mediating Psychological Processes

9

10

11

12

13

14

Michaël Dambrun

15

Université Clermont Auvergne, UBP, CNRS

16

17

18

19

20

21

22

23

24 Correspondence may be addressed to: Michael Dambrun Université Clermont Auvergne, 34

25 avenue Carnot, 63037 France. Email: michael.dambrun@univ-bpclermont.fr 
27 The main objective of this research was to test central assumptions from the Self-

centeredness/Selflessness Happiness Model. According to this model, while self-centered former, and both emotional stability and feelings of harmony in the case of the latter. These hypotheses were tested in two studies based on heterogeneous samples of citizens $(n=547)$.

34 Factor analyses revealed that self-centeredness (assessed through egocentrism and materialism) and selflessness (assessed through self-transcendence and connectedness to other) were two distinct psychological constructs. Second, while self-centeredness was positively and significantly related to fluctuating happiness, selflessness was positively and significantly related to authentic-durable happiness. Finally, distinct psychological processes mediated these relationships (study 2). On one hand, the relationship between selfcenteredness and fluctuating happiness was fully mediated by afflictive affects. On the other hand, emotional stability and the feeling of being in harmony partially mediated the relation between selflessness and authentic-durable happiness. 


\section{Introduction}

With the rise of positive psychology, the study of subjective well-being and happiness has emerged as a research topic of primary importance in psychology (e.g. [1-3]). In this perspective, Dambrun and Ricard [4] proposed the Self-centeredness/Selflessness Happiness Model (SSHM). The objective of the present study was to test three main assumptions of the SSHM: (1) self-centeredness and selflessness are not simple opposites, but are distinct psychological constructs; (2) sustainable authentic happiness would be promoted by a selfless style of functioning, while fluctuating happiness would be induced by self-centered functioning; and (3) independent processes would mediate these specific relationships: emotional stability and feeling of being in harmony in the case of the former, and afflictive affects in the case of the latter. Let us now see in more detail the theoretical underpinnings of these hypotheses.

\section{Self-Centeredness and Selflessness}

The SSHM posits that happiness is intimately linked to self-consciousness states [5]. Based on the dichotomy between the minimal self and the narrative self (e.g. [6]), the SSHM specifies the psychological processes that arise from self-consciousness states and, ultimately, happiness [4-5]. According to Dambrun and Ricard [4], at least two qualities of happiness are connected and under the influence of two types of psychological functioning: the selfcentered psychological functioning (Self-centeredness) and the selfless psychological functioning (Selflessness). There is little likelihood that these two types of functioning can operate simultaneously, the two having a tendency to be in conflict and in opposition to each other. However, they are proposed to consist of specific characteristics, which generate 


\section{Manuscript to be reviewed}

76 qualitatively different processes. For this reason, it is predicted that these two types of

77 functioning would emerge on two distinct dimensions. The first goal of this study was to

78 verify the bi-dimensionality of self-centeredness and selflessness. In statistical terms, the

79 SSHM predicts a two factor solution in a factor analysis rather than a single factor solution,

80 with characteristics assessing self-centeredness loading on one dimension and those assessing

81 selflessness loading on a second factor (hypothesis 1).

The Self-Centered Psychological Functioning and The Mediating Role of Afflictive

83

84

85

86

87

88

89

90

91

92

93

94

95

Affects. The perception of the self as a real entity with sharp boundaries underlies a selfcentered psychological functioning. Laborit [7] proposes that each entity (or organized

structure in the form of an entity), which aims at its preservation, is led to favor gratifications that positively reinforce it, and to avoid disagreeable things that threaten its homeostasis. A self-centered functioning, which is intimately related to egoism, egocentrism, an exaggerated importance given to the self and ego-inflation (through material possessions for example), favors and strengthen the "hedonic principle" (e.g. [8]). According to this principle, individuals are motivated to obtain pleasure (i.e. approach) and to avoid displeasure (i.e. avoidance). Attaining these objectives (i.e. obtaining gratification and avoiding disagreeable stimuli) creates a feeling of transitory pleasure, joy and satisfaction. However, these stimulusdriven pleasures are contingent upon the appearance or disappearance of certain stimuli [9]. The experience of pleasure is, by nature, fleeting and dependent upon circumstances. It is unstable and the sensations it evokes soon become neutral (i.e. hedonic adaptation, e.g. [1011]). In addition, the impossibility of attaining valued objectives gives rise to afflictive affects such as frustration, anger, hostility or jealousy, which damage well-being (e.g. [12]). Thus, by trying to maximize pleasures and avoiding displeasures, self-centeredness induces a fluctuating happiness in which phases of pleasure and displeasure alternate repeatedly [13]. Momentary-level scores show that reported happiness varies significantly both with the time 
101 of day and day of week. While particular activities significantly increase happiness, others are

102

103

104

105

106

107

108

110

111

112

113

114

115

116

associated with a decrease in happiness, with the result being that there are important

fluctuations in happiness over the course of a day or week [1]. Under this perspective,

Dambrun et al. [13] developed a subjective fluctuating happiness scale (i.e. the SFHS), assessing perceived degrees of variation in happiness. According to the SSHM, selfcenteredness would be positively and significantly related to this scale (hypothesis 2).

Moreover, the relationship between self-centeredness and subjective fluctuating happiness would be mediated, at least partially, by afflictive affects (hypothesis 3).

Some results provide preliminary support for these predictions. First, Dambrun et al.

[13] found that self-centered values such as Schwartz's self-enhancement values (i.e., achievement and power, e.g. [14-15]) were related to subjective fluctuating happiness. In a second study, Dambrun and Ricard [16] revealed that a scale assessing afflictive affects and composed of fifteen afflictive emotions (e.g. hostility toward other, jealousy, personal frustration) was positively and significantly related to the subjective fluctuating happiness scale. Thus, it is possible that afflictive affects mediate the relationship between selfcenteredness and subjective fluctuating happiness.

\section{The Selfless Psychological Functioning and The Mediating Role of Both Emotional}

Stability and Harmony Feeling. The SSHM [4] postulates the existence of a second self-based psychological functioning namely "selflessness". Unlike the self-centered functioning, "selflessness" is based on a weak distinction between self and others, and between self and the environment as a whole, which takes the form of a sense of connectedness (e.g. [17]).

Selflessness is closely related to self-transcendence (e.g. [18-20]). Selflessness would be primarily guided by the principle of "harmony", in the sense that the individual is facing a harmonious adjustment ${ }^{1}$ with the different elements of the environment, including others and the different forms of life [17], as well as their deep personal aspirations. This principle would 


\section{Manuscript to be reviewed}

126 guide all psychological activities (i.e. conation, motivation, attention, emotion, cognition,

127 behavior). For example, on an emotional level, the principle of harmony is linked to emotions

128 of benevolence, as empathy, compassion or deep respect. Several studies show that pro-social

129 behaviors, which are influenced by benevolent affects (e.g. [21]), are not only beneficial to

130 others but also for the individual themselves. They are associated with better well-being (e.g.

$131[16,22])$, positive emotions [23] and a reduction in psychological distress [24]. Similarly,

132 nature-connectedness is positively associated with well-being (e.g. [25]).

133 According to the SSHM, selflessness would be positively and significantly related to

134 authentic-durable happiness. Authentic happiness is understood, here, as an optimal way of

135 being; a state of durable contentment and plenitude or inner peace (based on a quality of

136 consciousness, which underlies and imbues each experience, emotion and behavior, and

137 allows us to embrace all the joys and the pain with which we are confronted). Under this

138 perspective, Dambrun and his colleagues [13] developed the Subjective Authentic-Durable

139 Happiness Scale (SA-DHS) for assessing subjective authentic-durable happiness. As

140 expected, they found that this scale was positively and significantly related to selfless values,

141 such as benevolence and universalism (i.e. self-transcendence values, e.g. [14-15]).

142 Interestingly for our purpose, using the Self-Transcendence Inventory (STI; [19]) as a marker

143 of selflessness, Dambrun and Ricard [16] found that self-transcendence was positively and

144 significantly related to subjective authentic-durable happiness. Thus, selflessness would be

145 positively and significantly related to authentic-durable happiness. Because subjective

146 authentic-durable happiness is theorized as a specific consequence of a selfless functioning, it

147 is predicted they will be positively and significantly related even when self-centeredness will

148 be statistically controlled for (Hypothesis 4). Similarly, because subjective fluctuating

149 happiness is theorized as a specific marker of a self-centered functioning, it is predicted that 
150 self-centeredness will be positively and significantly related to subjective fluctuating

151 happiness even when selflessness will be statistically controlled for (Hypothesis 2).

154 being in harmony.

First, benevolent affects, induced by the harmony principle, are not very sensitive to changes in the environment. As noted by Sprecher and Fehr [26]: "compassionate love may be experienced for someone to whom love is not reciprocated" (p. 228). This type of affect would be relatively stable and would contribute to emotional stability and lasting happiness. Similarly, connectedness to others has been found to correlate modestly, but positively, with emotional stability [17]. Several works have examined the relationship between emotional

161 stability and well-being. In these studies, emotional stability is mostly assessed by scoring the neuroticism factor of the big five inventory in the opposite direction. For example, Hills and Argyle [27] reported that emotional stability was the greater correlate of happiness among the 164 big five factors. Similarly, in a meta-analysis, DeNeve and Cooper [28] found that emotional 165 stability was the strongest predictor of life satisfaction and happiness. On the basis of the 166 SSHM, it is predicted that the relationship between selflessness and subjective authentic167 durable happiness would be mediated, at least partially, by emotional stability (hypothesis 5). In addition, Dambrun and Ricard [4] propose that selflessness promotes the feeling of

169 being in harmony with the environment (including others) and with oneself. This process also 170 would mediate the relationship between selflessness and authentic-durable happiness. The 171 perception of harmony, feelings of harmony and their relationships with happiness are present 172 in various cultural traditions. Harmony has been approached as equilibrium, a state of 173 homeostasis [29]. In the Yin-Yang theory, homeostasis is the ideal state for the entire 174 universe, a state of harmony with the great natural principles [30]. In psychological terms, it 


\section{Manuscript to be reviewed}

175 seems possible to distinguish three different levels of harmony: (1) being in harmony with

176 oneself, (2) interpersonal or social harmony and (3) being in harmony with the world,

177 including both the natural environment and the universe. These three levels are fundamental

178 in numerous Asian philosophies (e.g. [31]). Harmony with oneself (e.g. Body-mind harmony

179 or knowledge-feeling-idea harmony) has been proposed to be the essential characteristic of

180 healthy and happy people (see [32]), as well as of harmonious society [33]. It is proposed that

181 each level of perceived harmony (cognitive component; see [34]) contributes to the feeling of

182 being in harmony (affective component). Being in resonance with its profound aspirations can

183 favor the feeling of being in harmony with oneself. Being connected to others and feeling

184 empathy or compassion can promote the feeling of being in harmony with others. Being

185 connected to the natural world and to the universe can lead to the feeling of being in harmony

186 with the nature and the cosmos. These types of feeling are intimately linked with the

187 characteristics of sustainable and authentic happiness as serenity or inner peace, a dimension

188 of happiness that remains relatively unexplored (see [13]). Thus, on the basis of the SSHM, it

189 is predicted that the feeling of being in harmony (affective component) would mediate, at

190 least partially, the relationship between selflessness and subjective authentic-durable

191 happiness (hypothesis 6).

192

Overview of the Present Research.

In order to assess self-centeredness and selflessness, various measures were used. In the

194 seminal theoretical paper of 2011 [4], three main dimensions defined self-centeredness: a self-

195 centrism bias (i.e. the self takes on a central point of reference with regard to various

196 psychological activities), an exaggerated sense of importance given to the self (e.g.

197 considering that one's own condition is more important than that of others and that this takes

198 unquestionable priority) and an hedonic process (i.e. approach of gratifying stimuli and

199 avoidance of disagreeable ones). Across two studies, a measure of egocentrism and a scale of 
200 materialism were used to assess self-centeredness. While the first measure has been

201 previously developed to assess the first two dimensions of self-centeredness (i.e. self-

202 centrality bias and an exaggerated sense of importance given to the self), the measure of

203 materialism was used to assess the motivation to obtain material pleasures that is involved in

204 the third dimension (i.e. hedonic process). Theoretically, selflessness has at least two

205 important characteristics. First, its functioning is based on a weak distinction between self and 206 others, and between self and the environment as a whole. Second, it is intimately related to 207 self-transcendence; the process of seeing things as they are with clear awareness without 208 strong distortion coming from biological and social conditioning (see [4]). Therefore, a 209 measure of self-transcendence and a scale assessing connectedness to other and to nature were 210 incorporated in order to assess these two aspects of selflessness. While the connectedness 211 scale allowed us to assess the first component of selflessness, the self-transcendence scale 212 permitted us to measure the second. Because self-centeredness and selflessness tend to be in 213 opposition, while also generating qualitatively distinct processes, a two factors solution with a 214 moderate negative correlation between the two dimensions was predicted (Hypothesis 1). This 215 prediction will be tested in two studies by means of factor analyses.

216 The second aim of the present research was to examine the relationships between self217 centeredness/selflessness and subjective fluctuating happiness/subjective authentic-durable 218 happiness (Hypotheses 2 and 4). Study 1 was mainly designed to examine these relationships. 219 Finally, the third goal of the present research was to identify the underlying processes 220 mediating these relationships (i.e. Hypotheses 3, 5 and 6). The mediation hypotheses will be 221 specifically tested in study 2 by means of multiple mediation modeling [35].

224 centeredness and selflessness are distinct psychological construct that are not simple 
225 opposites on a single continuum. This prediction was tested using a factor analysis. (b) Self-

226 centeredness and selflessness would have specific happiness correlates. While subjective

227 fluctuating happiness is expected to correlate positively and significantly with self-

228 centeredness even when selflessness will be statistically controlled for, it is predicted that

229 selflessness would be positively and significantly related to subjective authentic-durable

230 happiness even when self-centeredness will be statistically controlled for.

231 Method

Participants and Procedure. Two hundred and forty-three voluntary participants were

233 recruited for the study on a voluntary basis through personal contact. The study took place in

234 France. The sample was composed exclusively of adults from a regional community. They

235 were adequately heterogeneous in age, gender, education, religiosity and socio-economic

236 status (see Table 1). The questionnaire was delivered personally to each voluntary participant.

237 All participants had 24 hours to respond to the questionnaire and return it. This study

238 consisted in an anonymous survey of consenting adults. Thus, the data were analyzed

239 anonymously. This study has been approved by the Sud-EST VI statutory Ethics Committee

240 (2014-CE36 ; IRB00008526), according to French legal requirements L. 1121-1-2 and R

$241 \quad 1121-3$

Materials. The questionnaire mainly comprised six scales: two scales assessing

243 happiness (fluctuating happiness and authentic-durable happiness), two scales assessing

244 selflessness (self-transcendence and connectedness to other and to nature), and two scales

245 assessing self-centeredness (egocentrism and materialism). At the end of the questionnaire, all

246 the participants were asked to provide socio-demographic information (i.e. age, gender,

247 education level, religiosity, and SES).

248 Fluctuating Happiness. The 10-item Subjective Fluctuating Happiness Scale (SFHS; see [13])

249 was used to assess fluctuating happiness. Participants had to indicate how much they agreed 
250 (7) or disagreed (1) with each of the 10 statements. A single composite score of subjective

251 fluctuating happiness was computed by averaging responses to the 10 items (e.g. "My level of

252 happiness is rather unstable, sometimes high, sometimes low", "I have times when I swing

253 from moments of total bliss to much less satisfying moments"). The possible range of score is

254 from 1.0 to 7.0, with higher scores indicating greater fluctuating happiness. The reliability of

255 this scale was satisfactory $(\alpha=.92)$.

256 Authentic-Durable Happiness. The 16-item Subjective Authentic-Durable Happiness Scale

257 (SA-DHS), developed by Dambrun and colleagues [13], was used. Participants had to indicate 258 their regular level of happiness in their life on a 7-point scale, ranged from 1 (very low) to 7

259 (very high). The scale comprised 16 items with 13 positively valenced items (e.g. happiness,

260 bliss, overall well-being, serenity and plenitude), assessing authentic-durable happiness, and

2613 negatively valenced items, only used to control for the compliance bias. A single composite

262 score for subjective authentic-durable happiness was computed by averaging responses to the

26313 positively valenced items. The possible range of scores was from 1.0 to 7.0 , with higher

264 scores reflecting greater authentic-durable happiness. The reliability of this scale was

265 satisfactory $(\alpha=.94)$.

266 Self-Transcendence. The Adult Self-Transcendence Inventory (ASTI; $[19,36])$ was used to 267 assess self-transcendence. This instrument was adapted from English to French ${ }^{2}$. This scale 268 comprised 10 items ("My peace of mind is not so easily upset as it used to be", "I feel that my 269 individual life is a part of a greater whole"). Participants were asked the extent to which they 270 agree with each statement compared to five years ago, on a 7-point Likert scale ranging from

2711 (strongly disagree) to 7 (strongly agree). The reliability of this scale was satisfactory $(\alpha=$ $272.76)$

273 Connectedness. To measure the level of participants' connectedness, the Allo-Inclusive 274 Identity scale developed by Leary, Tipsord, \& Tate [17] was used. This instrument was 


\section{Manuscript to be reviewed}

275 adapted from English to French ${ }^{2}$. This scale comprised 16 items assessing how people

276 perceived "connection" or "relatedness" to other people (first dimension) and to the

277 nonhuman natural world (second dimension). These two dimensions reflect two distinct

278 subscales, each comprising 8 statements: connectedness to other (e.g. "the connection

279 between you and your best friend of the other sex") and connectedness to natural world (e.g.

280 "the connection between you and the earth"). For each statement describing the connection

281 between the respondent and some other entity, participants selected from a set of seven pairs

282 of circles, one circle representing the respondent and the second circle representing the other

283 entity ( $1=$ widest separation between the two; 7 = closest overlap between the two). The

284 reliability of each subscale was satisfactory (connectedness to other, $\alpha=.70$; connectedness to

285 natural world, $\alpha=.85)$.

286 Egocentrism. To assess egocentrism, the scale developed by Dambrun [37] was used. This

287 scale comprised 10 statements (e.g. "The motto "me first, then the others" corresponds quite

288 well to the way in which I behave", "I'm not someone who tries systematically to make the

289 best personal profit of a situation (reverse coded)"). Participants were asked the extent to

290 which they agree with each statement on a 7-point scale ranging from 1 (strongly disagree) to

2917 (strongly agree). The reliability of this scale was satisfactory $(\alpha=.80)$.

292 Materialism. To assess materialism, 9 items from the material value scale (MVS) proposed by

293 Richins [38] (see also [39]) were used. This scale assesses three dimensions: possession-

294 defined success (e.g. "Some of the most important achievements in life include acquiring

295 material possessions"), acquisition centrality (e.g. "I usually buy only the things I need") and

296 acquisition as the pursuit of happiness (e.g. "My life would be better if I owned certain things

297 I don't have"). This scale was adapted from English to French ${ }^{2}$. Participants were asked the

298 extent to which they agree with each statement on a 7-point scale ranging from 1 (strongly

299 disagree) to 7 (strongly agree). The reliability of this scale was satisfactory $(\alpha=.76)$. 
300 All statistical analysis was performed using SPSS v.22.0 (IBM Corp., Armonk, NY, USA).

$301 \quad$ Results

Relationships between Various Measures. First, the means, standard deviations, and

303 inter-correlations among all the measured variables were examined (see Table 2). First, while

304 egocentrism and materialism correlated positively and significantly with fluctuating happiness

305 (respectively $r=.40$ and $r=.21$ ), self-transcendence and connectedness to others were

306 positively and significantly related to authentic-durable happiness (respectively $r=.34$ and $r$

$307=.23$ ) but not to fluctuating happiness. Materialism was not related to authentic-durable

308 happiness. However, egocentrism and authentic-durable happiness were negatively

309 correlated. In this study, connectedness to nature was not significantly related to happiness.

310 Replicating previous studies, subjective fluctuating happiness and subjective authentic-

311 durable happiness were significantly and negatively correlated $(r=-.50)$. Finally and as

312 predicted, while the main psychological constructs related to selflessness were positively and

313 significantly related to each other (i.e. self-transcendence and connectedness to other), those

314 assessing self-centeredness were also positively and significantly related to each other (i.e.

315 egocentrism and materialism). Unexpectedly, connectedness to nature was not related to self-

316 transcendence. For this reason, this measure was not included in further analyses.

317 Are Self-centeredness and Selflessness distinct constructs? In order to test the predicted

318 model, a factor analysis was performed. This analysis hypothesized that self-transcendence

319 and connectedness to other formed one component assessing selflessness, and that this was

320 distinct from a second factor assessing self-centeredness and composed of egocentrism and

321 materialism. The principal component factor analysis with direct Oblimin rotation of the four

322 scales disclosed two factors with Eigenvalues greater than 1. The first factor accounted for

$32342.5 \%$ of the explained variance and regrouped the measures of materialism and egocentrism

324 (Eigenvalue =1.7; factor loadings respectively .88 and .76). The second factor accounted for 
$32525.9 \%$ of the explained variance and regrouped the measures of connectedness to others and

326 the self-transcendence inventory (Eigenvalue $=1.04$; factor loadings respectively .87 and .72 ).

Happiness and Subjective Authentic-Durable Happiness? In order to examine the hypotheses

regarding the relationships between self-centeredness, selflessness, subjective fluctuating

happiness and subjective authentic-durable happiness, first the mean of self-centeredness was

selflessness was computed by averaging the measures of connectedness to other and self-

334 calculated using multiple regression analyses (see Table 3).

It was predicted that self-centeredness would be positively and significantly related to

336 fluctuating happiness even when selflessness will be statistically controlled for. On the other

337 hand, it was hypothesized that selflessness would be positively and significantly related to

338 authentic-durable happiness even when self-centeredness will be statistically controlled for.

339 Selflessness was positively and significantly related to authentic-durable happiness $(\beta=.36$,

$340 p<.001)$, but not to fluctuating happiness $(\beta=-.07, p>.28)$. When self-centeredness was

341 statistically controlled for, the relationship between selflessness and authentic-durable

342 happiness still remained significant $(\beta=.37, p<.001)$. Self-centeredness was significantly

343 related to both fluctuating happiness $(\beta=.36, p<.001)$ and authentic-durable happiness $(\beta=$

$344-.17, p<.01)$. When selflessness was statistically controlled for, the relationship between self-

345 centeredness and authentic-durable happiness vanished $(\beta=-.08, p>.18)$, and the

346 relationship between self-centeredness and fluctuating happiness still remained significant $(\beta$

$347=.33, p<.001)$. Self-centeredness and selflessness were significantly and negatively

348 correlated $(\beta=-.25, p<.001)$.

349 Discussion 
As predicted on the basis of the SSHM, the various psychological constructs assessing

351 selflessness and self-centeredness load on two distinct factors. While self-transcendence and

352 connectedness to other load on the selflessness dimension, both egocentrism and materialism,

353 appropriately, load on the self-centeredness factor. These two dimensions correlated

354 negatively and modestly. They share approximately 6 percent of variance. These results

355 confirm the first hypothesis and are compatible with the SSHM position that selflessness and

356 self-centeredness are not simple opposites, but rather are distinct modes of psychological

357 functioning that tend to be opposite (i.e. partial opposite).

If selflessness and self-centeredness are distinct modes of psychological functioning,

359 they would result in distinct outcomes. This is exactly what it is found when the relationships

360 between these modes of psychological functioning and happiness were examined. More

361 precisely, selflessness was positively and moderately related to subjective authentic-durable

362 happiness even when self-centeredness was statistically controlled for. Selflessness was not

363 related to subjective fluctuating happiness. On the other hand, when selflessness was

364 statistically controlled for, self-centeredness was positively and moderately related to

365 subjective fluctuating happiness, but not to subjective authentic-durable happiness. Thus, both

366 selflessness and self-centeredness seem to have their unique happiness marker, subjective

367 authentic-durable happiness in the case of the former and subjective fluctuating happiness in

368 the case of the latter. These results confirm the hypotheses 2 and 4.

This second study was mainly designed to identify the mediating processes by which

371 selflessness is positively related to subjective authentic-durable happiness and by which selfcenteredness is positively related to subjective fluctuating happiness. To the extent that

373 reproducibility has been identified as a strong issue in psychology (see for example [40]), a 
374 second objective of study 2 was to test the reproducibility of the results obtained in study 1 by

375 reproducing similar statistical analyses.

376 Method

Participants and Procedure. Three hundred and four voluntary participants were

378 recruited for the study on a voluntary basis through personal contact. The study took place in

379 France. The sample was composed exclusively of adults from a national community. They

380 were adequately heterogeneous in age, gender, education, religiosity and socio-economic

381 status (see Table 1). The questionnaire was delivered personally to each voluntary participant

382 via a paper booklet $(n=153)$ or an online survey platform $(n=151)$. All participants had 24

383 hours to respond to the questionnaire and return it. This study consisted in an anonymous

384 survey of consenting adults. Thus, the data were analyzed anonymously. This study has been

approved by the Sud-EST VI statutory Ethics Committee (2014-CE36 ; IRB00008526), according to French legal requirements L. 1121-1-2 and R 1121-3.

Materials. In addition to the measures used in study 1 (i.e. fluctuating happiness,

388 authentic-durable happiness, self-transcendence, connectedness to other and to nature,

389 egocentrism and materialism), three new scales were added. These new instruments assess the

390 predicted mediating variables (i.e. afflictive affects, feeling of being in harmony, and

391 emotional stability). At the end of the questionnaire, all the participants were asked to provide

392 socio-demographic information (i.e. age, gender, education level, religiosity, and SES).

393 Happiness. The 10-item Subjective Fluctuating Happiness Scale (SFHS; see [13]) was also

394 used in this study. The reliability of this scale was satisfactory $(\alpha=.92)$. The 16 -item

395 Subjective Authentic-Durable Happiness Scale (SA-DHS), developed by Dambrun and

396 colleagues [13], was also used. The reliability of this scale was satisfactory $(\alpha=.95)$. 
397 Self-Centeredness. As in study 1, both the material value scale (MVS), proposed by Richins

398 [38], and the 10-item egocentrism scale, developed by Dambrun [37], were used. Their

399 reliability was adequate (respectively $\alpha=.74$ and $\alpha=.78$ ).

400 Selflessness. Again, the 10-item Adult Self-Transcendence Inventory (ASTI, [19, 36]) and the

401 Allo-Inclusive Identity scale, developed by Leary, Tipsord, \& Tate [17], were incorporated in

402 the questionnaire. The reliability of the ASTI was satisfactory $(\alpha=.79)$. The reliability of

403 each subscale of the Allo-Inclusive Identity scale also was adequate (connectedness to others,

$404 \alpha=.79$; connectedness to natural world, $\alpha=.90)$.

405 Mediating Variables. Three scales assessing the predicted mediating processes were added to

406 the questionnaire: afflictive affects, feeling of being in harmony and emotional stability. Each

407 scale was presented separately.

408

Afflictive affects. To assess afflictive affects, the scale developed by Dambrun and

409 Ricard [16] was used. This scale comprised 15 statements (e.g. "hostility toward other"

410 jealousy", "personal frustration", "angry”, “fear", “threat"). Participants had to indicate their

411 regular level for each type of affect on a 7-point scale ranged from 1 (very low) to 7 (very

412 high). The reliability of each subscale was satisfactory $(\alpha=.86)$.

413 Feeling of being in harmony. To assess the feeling of being in harmony, a recent scale

414 developed by Dambrun [41] was used. This scale consists in 25 statements assessing harmony

415 feeling in various domains (e.g. "I feel a perfect harmony between my ideals and my current

416 life", "when I observe the sky during the night, I often feel a feeling of harmony", "I feel that

417 my personal relationships with the person that share my life are almost harmonious", "I feel

418 that my interpersonal relationships are rarely harmonious (reverse coded)"). Participants were

419 asked the extent to which they agree with each statement on a 7-point scale ranging from 1

420 (strongly disagree) to 7 (strongly agree). The reliability of this scale was satisfactory $(\alpha=$

421 .86). Since, in this study, assessing the feeling of being in harmony was the main interest, the 


\section{Manuscript to be reviewed}

422 Harmony in Life Scale of Kjell and colleagues [34], which is more focused on the cognitive

423 component of harmony (e.g. "I am in harmony"), was not used.

Emotional Stability. To assess emotional stability, the neuroticism factor of the big

425 five inventory was measured and scored in the opposite direction, such that higher scores

426 indicate greater emotional stability (for a similar methodology see, for example, [27]).

427 Specifically, the French version of the big five inventory, developed and validated by

428 Plaisant, Courtois, Réveillère, Mendelsohn, and John [42], was used. Participants had to

429 indicate the extent to which they approve each statement on a 5-point scale ranging from 1

430 (strongly approve) to 5 (strongly disapprove). The reliability of this scale was adequate $(\alpha=$ $431 \quad .84)$.

432 All statistical analysis was performed using SPSS v.22.0 (IBM Corp., Armonk, NY,

433 USA).

434 Results

Relationships between Various Measures. First, the means, standard deviations, and

436 inter-correlations among all the measured variables were examined (see Table 4). While

437 egocentrism and materialism correlated positively and significantly with fluctuating happiness

438 (respectively $r=.17$ and $r=.17$ ), self-transcendence and connectedness to other were

439 positively and significantly related to authentic-durable happiness (respectively $r=.45$ and $r$

$440=.34$ ), but not to fluctuating happiness. As expected, subjective fluctuating happiness and

441 subjective authentic-durable happiness were significantly and negatively correlated $(r=-.27)$.

442 It was examined how the predicted mediating variables correlated with other measures.

443 As predicted, afflictive affects mainly correlated positively and significantly with egocentrism

$444(r=.44)$, materialism $(r=.20)$ and subjective fluctuating happiness $(r=.36)$. As expected,

445 feelings of being in harmony were positively and significantly related to self-transcendence $(r$ $446=.39)$, connectedness to others $(r=.42)$ and to nature $(r=.47)$, and subjective authentic- 
447 durable happiness $(r=.59)$. However, significant negative correlations emerged between the

448 measure of harmony feeling and both materialism $(r=-.18)$ and subjective fluctuating

449 happiness $(r=-.23)$. The third mediating variable (i.e. emotional stability) was mainly related

450 to self-transcendence $(r=.34)$, connectedness to other $(r=.21)$, subjective fluctuating

451 happiness $(r=-.59)$, subjective authentic-durable happiness $(r=.55)$, afflictive affects $(r=-$

$452.29)$ and feelings of being in harmony $(r=.41)$.

Finally, while the main psychological constructs related to selflessness were positively

454 and significantly related to each other (i.e. self-transcendence and connectedness to other),

455 those assessing self-centeredness also were positively and significantly related to each other

456 (i.e. egocentrism and materialism). Again, connectedness to nature was not related to self-

457 transcendence. For this reason, this measure was not included in further analyses.

Are Self-centeredness and Selflessness distinct constructs? In order to further test the predicted model, again, a factor analysis was performed. This analysis hypothesized that selftranscendence and connectedness to others formed one component assessing selflessness, and that this was distinct from a second factor assessing self-centeredness and composed of

462 egocentrism and materialism. The principal component factor analysis with direct Oblimin

463 rotation of the four scales disclosed two factors with Eigenvalues greater than 1 . The first

464 factor accounted for $35.5 \%$ of the explained variance and regrouped the measures of

465 connectedness to other and the self-transcendence inventory (Eigenvalue $=1.4$; factor

466 loadings respectively .84 and .82). The second factor accounted for $30.3 \%$ of the explained

467 variance and regrouped the measures of materialism and egocentrism $($ Eigenvalue $=1.2$;

468 factor loadings respectively .80 and .77). Are Self-centeredness and Selflessness Related Respectively to Subjective Fluctuating

470 Happiness and Subjective Authentic-Durable Happiness? Using the same procedure than in

471 study 1, the relationships between self-centeredness (i.e. average of materialism and 
472 egocentrism), selflessness (i.e. average of connectedness to other and self-transcendence),

473 subjective fluctuating happiness and subjective authentic-durable happiness were examined

474 (see Table 5$)^{3}$. As expected, selflessness was positively and significantly related to authentic-

475 durable happiness $(\beta=.48, p<.001)$, even when self-centeredness was statistically controlled

476 for $(\beta=.48, p<.001)$. Selflessness and fluctuating happiness were not significantly related $(\beta$

$477=-.02, p>.77)$. Self-centeredness was positively and significantly related to fluctuating

478 happiness $(\beta=.22, p<.001)$, even when selflessness was statistically controlled for $(\beta=.22$,

$479 p<.001)$. Self-centeredness was not related to authentic-durable happiness $(\beta=-.07, p>.22)$.

480 Self-centeredness and selflessness were not significantly correlated $(\beta=-.07, p>.21)$.

481 Mediation Analyses. In order to test the predicted multiple mediator models, the

482 procedure advocated by Preacher and Hayes [35] was followed (5000 samples and confidence

483 intervals $=95 \%$ ). The averaged measure of self-centeredness (i.e. materialism and

484 egocentrism) and selflessness (i.e. connectedness to other and self-transcendence) ${ }^{3}$ were used.

485 As previously mentioned, the measure of afflictive affects was significantly related to

486 fluctuating happiness, but not to authentic-durable happiness. Feeling of harmony and

487 emotional stability were significantly related to authentic-durable happiness, but also to

488 fluctuating happiness (see Table 4). The scale of afflictive affects was significantly related to 489 self-centeredness $(\beta=.40, p<.001)$, but not to selflessness $(\beta=.01)$. Emotional stability and 490 feeling of harmony were positively and significantly related to selflessness (respectively, $\beta=$ $491.33, p<.001$ and $\beta=.49, p<.001)$, but they were also significantly and negatively related to 492 self-centeredness (respectively, $\beta=-.13, p<.02$ and $\beta=-.15, p<.01$ ).

493 Thus, the first predicted mediation model in which afflictive affects would mediate the 494 relationship between self-centeredness and fluctuating happiness was tested. However, since 495 both harmony feeling and emotional stability correlated significantly and negatively with both 496 self-centeredness and fluctuating happiness, they were added as potential mediators in the 
497 Preacher and Hayes [35] multiple mediation procedure with self-centeredness as an

498 independent variable and fluctuating happiness as a dependent variable (see Figure 1a). When

499 afflictive affects, feeling of harmony and emotional stability were statistically controlled for,

500 the relationship between self-centeredness and fluctuating happiness became non-significant

$501(\mathrm{~b}=.13, \mathrm{se}=.08, p<.11)$ and was significantly reduced $(\mathrm{b}=.23, \mathrm{se}=.07 ; z=3.42, p<.001$;

$502 C I: .09 ; .38)$. As predicted, only afflictive affects significantly mediated this relationship $(\mathrm{b}=$

$503.11, \mathrm{se}=.04 ; z=3.04, p<.003 ; C I: .04 ; .20)$. Based on their bootstrap confidence intervals,

504 harmony feeling and emotional stability did not mediate this relationship $(b=.00, \mathrm{se}=.01$;

$505 C I:-.03 ; .03$ for harmony feeling, and $\mathrm{b}=.11, \mathrm{se}=.03 ; C I: .00 ; .23$ for emotional stability).

506 This model explains 39\% of variance in term of subjective fluctuating happiness. Providing

507 additional support, the results did not provide a stronger support for the reversed model, in

508 which afflictive affects mediate the relationship between fluctuating happiness (IV) and self-

509 centeredness $(\mathrm{DV} ; \mathrm{b}=.08, \mathrm{se}=.02 ; C I: .04 ; .12)$, than for the predicted model $(\mathrm{b}=.21$, se $=$

$510 \quad .05 ; C I: .12 ; .32$; see Figure $1 \mathrm{~b})$.

511 The second predicted mediation model in which both feelings of harmony and

512 emotional stability would mediate the relationship between selflessness and subjective

513 authentic-durable happiness also was tested. Feelings of harmony and emotional stability

514 were entered as mediators in a Preacher and Hayes [35] multiple mediation procedure, with

515 selflessness as an independent variable and authentic-durable happiness as a dependent

516 variable (see Figure 2). When feelings of harmony and emotional stability were statistically

517 controlled for, the relationship between selflessness and authentic-durable happiness

518 remained statistically significant $(b=.28, \mathrm{se}=.07, \mathrm{p}<.001)$, but was significantly reduced $(\mathrm{b}$ $519=.41, \mathrm{se}=.05 ; z=7.55, p<.001 ; C I: .31 ; .53)$. As predicted, both feelings of harmony $(\mathrm{b}=$ $520.25, \mathrm{se}=.04 ; z=5.84, p<.001 ; C I: .18 ; .35)$ and emotional stability $(\mathrm{b}=.16, \mathrm{se}=.03 ; z=$

$5214.70, p<.001 ; C I: .09 ; .24)$ were significant and independent mediators of this relationship. 
522 This model explains $49 \%$ of variance in authentic-durable happiness. Providing additional

523 support for this model, the results did not provide a stronger support for the reversed model,

524 in which harmony feeling and emotional stability mediated the relationship between

525 authentic-durable happiness (IV) and selflessness (DV; $\mathrm{b}=.15, \mathrm{se}=.03 ; z=4.51, p<.001$;

$526 C I: .08 ; .22)$. Moreover, in this reversed model, emotional stability did not mediate the

527 relationship between the IV and the DV $(\mathrm{b}=.02$, se $=.02 ; z=1.01, p>.31 ; C I:-.02 ; .07)$.

528 Discussion

529 The results obtained in Study 1 are reproduced in this second study. First, the model in

530 which selfless and self-centered psychological constructs load on two separate dimensions is

531 supported by the data. Second, while selflessness was only related to subjective authentic-

532 durable happiness, self-centeredness only correlated with subjective fluctuating happiness.

533 Thus, using two samples, similar findings were found, suggesting that they are robust.

In addition, Study 2 reveals the main underlying psychological processes of the

relationships between self-based psychological functioning and happiness. As predicted, the

relationship between self-centeredness and subjective fluctuating happiness was fully

537 mediated by afflictive affects. According to the SSHM, by favoring afflictive affects, self-

538 centeredness would enhance fluctuations in term of happiness. Despite the impossibility to

539 draw a causal conclusion due to the nature of the correlational design, the results of this

540 second study are compatible with this interpretation. In addition, it was found that the

541 relationship between selflessness and authentic-durable happiness was significantly mediated

542 by both emotional stability and feelings of being in harmony. Interestingly, these two

543 variables were two independent mediators. However, controlling for these two variables, the

544 direct effect between selflessness and authentic-durable happiness remained statistically

545 significant. This suggests that other processes are probably involved in this relationship. 
546 Future research may examine this possibility. Together, these results validate the hypotheses

$547 \quad 3,5$ and 6.

548 While self-centeredness and selflessness are related to distinct happiness outcomes

549 through distinct processes (i.e. afflictive affects and feeling of being in harmony), the role of

550 emotional stability seems to be less exclusive. While emotional stability appears to be directly

551 involved in the selflessness functioning, it also seems that it operates in self-centeredness,

552 albeit at a more indirect level. While emotional stability did not significantly mediate the

553 relationship between self-centeredness and fluctuating happiness, this construct was

554 significantly related to both afflictive affects (around $12 \%$ of common variance) and

555 fluctuating happiness (around 31\% of common variance). This suggests a moderate overlap

556 between self-centeredness and selflessness. While these two constructs did not correlate

557 significantly in this study, it seems that both involved, at different levels, emotional

558 (in)stability.

General discussion.

In recent decades, the study of well-being and happiness has gradually emerged as a

561 central topic in psychology. One of the substantive questions underlying the research

562 concerns the conditions for achieving happiness. The main current psychological theories

563 emphasize the importance of several factors. For example, self-determination theory [43] (see

564 also [44]) proposes that happiness and well-being are intimately linked to the achievement of

565 three basic needs: autonomy, competence and relatedness. From the perspective of

566 psychological well-being, Ryff and Singer [45] highlight six key factors: self-acceptance,

567 positive relationships, mastering one's environment, autonomy, having a purpose in life and

568 personal growth. Waterman [46] emphasizes the importance of carrying out activities that

569 allow one to feel alive, to be engaged and fulfilled (e.g. [47]). Rather than focusing on the

570 "psychological qualities" that achieve happiness, the SSHM takes into account the nature of 
571 the self and its resulting psychological processes. Specifically, it is argued that: (a)

572 psychological functioning depends, at least in part, on the structuring of the self (more

573 fundamentally of the "experienced self") and (b) the authentic-durable happiness, the state of

574 plenitude and serenity, would be favored by selflessness, while fluctuations in term of

575 happiness would be enhanced by self-centeredness. The results presented in this paper

576 provide a preliminary support for these hypotheses. Let us see in more detail the main results

577 of these two studies and their main limitations.

Self-centeredness and Selflessness are Distinct Psychological Constructs.

First, the theoretical model predicts the existence of two modes of psychological

580 functioning (i.e. self-centeredness and selflessness) that tend to be opposed, but that they are

581 characterized by qualitative distinct psychological processes. In two studies, results of factor analyses are compatible with this prediction. Each time, a two factors solution emerged with constructs related to self-centeredness loading on one factor and those assessing selflessness loading on a second factor. While these two factors were found to correlate negatively and modestly in Study 1 (i.e. around 6\% of common variance), they were found to be statistically unrelated in Study 2. Thus, they are not strictly independent, but they are not simple opposites

587 on a single continuum. While they tend to be opposed, they represent distinct psychological constructs. Consistently, the two types of happiness and the two self-based modes of psychological functioning indicate two relatively independent paths. While subjective

590 fluctuating happiness was related to self-centeredness (path 1), subjective authentic-durable

591 happiness was related to selflessness (path 2). The correlations were medium in size ${ }^{4}$. Finally, 592 these two paths were explained by two distinct processes: afflictive affects (for path 1) and 593 both feeling of being in harmony and emotional stability (for path 2 ). On the whole, these 594 results are consistent with the two paths theoretical model and question approaches based on a 595 single factor dimension, such as the quiet ego perspective (e.g. [48-49]) or the hypo-ego 
596 conception [50-51], which are manifestations of self-centeredness. Since a low level of self-

597 centeredness does not necessarily imply a high level of selflessness, it seems important not to

598 limit the investigations to self-centeredness (i.e. low/high self-centeredness continuum). A

599 more systematic differentiation between self-centeredness and selflessness processes seems to

600 represent a positive avenue for future research. For example, both the quiet ego and the hypo-

601 ego perspectives involve a sort of mindfulness attention: a "detached awareness" in the case

602 of the quiet ego approach and a "present-focused self-thought" in the hypo-ego perspective.

603 Based on the distinction between self-centeredness and selflessness, the theoretical model

604 proposes that distinct attention processes may be involved in these two self-based modes of

605 psychological functioning. While mindlessness through mental rumination [52], a wandering

606 mind [53] and the absence of meta-awareness (i.e. experiential fusion [54]) would be involved

607 in self-centeredness, selflessness would be more intertwined to a decentering attention [55-

608 56-57] and to mindfulness characteristics, such as attention to the present moment, acting

609 with awareness, concentration, non-distraction and the non-judgment of experience [57-58].

610 Future research may examine this possibility.

611 Self-Based Psychological Functioning and Happiness Outcomes.

612 Using the Schwartz's circumplex model of values [14], Dambrun and colleagues [13]

613 found that self-transcendence values (benevolence and universalism) were only related to

614 authentic-durable happiness, while self-enhancement values (power and achievement) were

615 only related to fluctuating happiness. The present results confirm these preliminary data with

616 a more powerful approach in which selflessness and self-centeredness were assessed multi-

617 dimensionally. In these studies, self-centeredness was inferred from egocentrism and

618 materialism. Self-transcendence and other-connectedness were aggregated in order to infer

619 selflessness. As expected, both dimensions were related to happiness outcomes in the

620 expected directions. By fostering authentic-durable happiness, selflessness represents a 


\section{Manuscript to be reviewed}

621 promising way to enhance health and well-being. Using various scales assessing well-being

622 and life satisfaction, authentic-durable happiness, particularly its inner-peace component, was

623 the only robust predictor of a biological marker of stress (i.e. cortisol, see [13]). Inner-peace

624 was associated with a lower level of cortisol, a steroid hormone involved in cardiovascular

625 disease. Thus, insofar as selflessness increases inner-peace, it could be a salutogenic factor for

626 health. On the other hand, self-centeredness is likely implied in the development of health

627 issues. In Study 2, both afflictive affects and subjective fluctuating happiness were

628 significantly related to neuroticism (i.e. emotional instability), a personality trait strongly

629 related to various psychological and health issues (e.g. [59]) and to mortality (e.g. [60]).

630 Negative affects, closely related to afflictive affects, are associated with somatic symptoms

631 and with an attention bias toward negative stimuli and threatening situations [61-62]. Thus, it

632 seems plausible that self-centeredness plays a role in health issues. Of course, much research

633 is needed and research programs aiming at examining the relationships between self-based

634 psychological functioning and various health issues must be profitably engaged.

635 The Underlying Processes.

636 An important contribution of this paper concerns the identification of some of the

637 mechanisms which explain the relationship between self-based psychological functioning and

638 happiness. Self-centeredness shares a non-negligible portion of variance with afflictive affects

639 (i.e. 16\%). As expected, these specific affects explained the relationship between self-

640 centeredness and fluctuating happiness. It would be interesting, in future research, to identify

641 the processes that explain the relationship between self-centeredness and these affects.

642 Several variables could be involved, such as mindlessness (rumination, wandering mind),

643 experiential avoidance [63] and susceptibility to ego-threat [51].

644 Selflessness was strongly and moderately related to two mediating variables:

645 respectively, feeling of being in harmony (around $24 \%$ of common variance) and emotional 
646 stability (around 11\% of common variance). In addition, these two mediating variables

647 correlated moderately to authentic-durable happiness. These results can be added to the

648 growing body of research confirming the traditional philosophies in which a state of harmony

649 is a superior principle of the human existence that is intimately linked to happiness (e.g. [34,

650 64-65]]). As presented in the introduction, at least three levels of harmony can be

651 distinguished: harmony with oneself, social harmony and harmony with the natural

652 environment, including the universe. Future research may examine which of these

653 components contributes the most to happiness [41]. It is also proposed to distinguish the

654 cognitive and affective components of harmony. While the cognitive component (i.e.

655 perceived harmony) is likely a prelude to affective harmony (i.e. feeling of being in

656 harmony), it is posited that only the affective component would be primarily related to

657 happiness. Because the cognitive component of harmony was not measured in this study, the 658 question still remains open.

659 It is likely that benevolent affects (e.g. empathy, compassion, respect) are involved in

660 the relation between selflessness and the two mediating variables. In a past study, it was

661 found that the relationship between the self-transcendence inventory and subjective authentic-

662 durable happiness was partially mediated by benevolent affects [16]. By improving

663 interpersonal relations, benevolent affects may enhance social harmony. Moreover, pro-

664 sociality is positively associated with emotional stability (e.g. [66]). Thus, benevolent affects

665 could explain, at least partially, why selflessness is related to both feelings of being in

666 harmony and emotional stability.

667 Limitations and Future Directions.

668 Of course, these studies have some limitations. First, both self-centeredness and

669 selflessness were respectively assessed through only two markers: egocentrism and

670 materialism for the former and connectedness to other and self-transcendence for the latter. 
671 Thus, it would be important to replicate the current findings by adding additional markers.

672 This would reinforce the present results. Second, these two studies are based on correlational

673 devices and heterogeneous samples of French citizens. Such a sampling has the advantage of

674 increasing the ecological validity of the results of these studies. However, because the present

675 design is correlational, it is impossible to provide strong claims about causality. Future studies

676 using experimental designs would increase the confidence in the causal direction between

677 self-based psychological functioning (i.e. self-centeredness and selflessness) and happiness

678 (i.e. fluctuating and authentic-durable). Encouraging results stem from a recent lab

679 experiment, which reveals that selflessness elicits happiness via dissolution of perceived body

680 boundaries. [5]. Since the SSHM predicts reciprocal influences between self-based

681 psychological functioning and happiness, experimental studies aiming at examining the

682 influence of happiness on self-based psychological functioning would be also welcome.

683 Nonetheless, these results provide significant empirical support for a part of the Self-

684 centeredness/Selflessness Happiness Model (SSHM).

685 This theoretical model predicts that changes in the experience of the embodied self

686 (from self-centeredness to selflessness) would lead to changes in emotional stability. The

687 results that demonstrate the mediating role of emotional stability in the relationship between

688 selflessness and authentic-durable happiness are compatible with this prediction, however,

689 experimental studies are needed to specifically test this hypothesis, which challenges the view

690 that personality traits are perfectly stable in adulthood (e.g. [67]). In this sense, the present

691 results are consistent with the growing body of research revealing both changes in personality

692 traits across the life course (e.g. [68-69]) and that personality traits and well-being can

693 reciprocally influence each other over time (e.g. [70]).

694 Using the experience sampling method, it would be relevant to reproduce the present

695 findings. According to the SSHM, self-centeredness and selflessness are not only related to 
696 distinct patterns of evaluated happiness, but also to distinct pattern of experienced happiness.

697 Thus, it would be relevant to examine the hypotheses derived from this model using the

698 experience sampling method. This approach minimizes the bias associated with the recovery

699 of memories and those associated with the development of global judgments (e.g. judgments

700 based on the most accessible memories, see [71]). In addition, these techniques provide

701 continuous monitoring of longitudinal samples in the short or long term that can permit

702 inferences regarding temporal relationships (e.g. [72]).

703

704

705

706

707

708

709

710

711

712

713

714

715

716

717

718

719

720 
$722{ }^{1}$ Harmony means there is perfect agreement between the diverse parts of whole. When the

723 self is perceived as being an interconnected element of the whole, a person's psychological

724 functioning becomes more mindful and respectful of all the elements comprising this whole.

725 Here the whole is meant in its broad sense. It is composed of the totality of elements, which

726 make up our environment, including not only oneself and other human beings, but also all

727 forms of natural life. In other words, the perception of interconnectedness underlies a specific

728 psychological functioning by which the individual adjusts harmoniously to all of the elements

729 (for more details, see [4]).

$730 \quad{ }^{2}$ First, the scale was translated into French and then back translated. Second, in order to verify

731 the internal consistency, prior to its incorporation into the present study, the scale was field-

732 tested with a sample of 75 participants. In this field test, the reliability of the Adult Self-

733 Transcendence Inventory (ASTI) was adequate $(\alpha=.89)$, the reliability of each subscale of

734 the Allo-Inclusive Identity scale also was satisfactory (connectedness to other, $\alpha=.77$;

735 connectedness to natural world, $\alpha=.86$ ), and the 9 items from the material value scale also

736 provided an adequate internal reliability $(\alpha=.77)$.

$737 \quad{ }^{3}$ The same basic findings were found using factor scores.

$738{ }^{4}$ Across the two studies, the mean correlation between self-centeredness and fluctuating

739 happiness was of .29 and the mean correlation between selflessness and authentic-durable

740 happiness was of .42 
References.

747 1. Csikszentmihalyi, M., \& Hunter, J. (2003). Happiness in Everyday Life: The Uses of

748 Experience Sampling. Journal of Happiness Studies, 4, 185-199.

749 2. Diener, E. (2000). Subjective well-being: The science of happiness, and a proposal for a $750 \quad$ national index. American Psychologist, 55, 34-43.

751 3. Lyubomirsky, S., Sheldon, K. M., \& Schkade, D. (2005). Pursuing happiness: The 752 architecture of sustainable change. Review of General Psychology, 9, 111-131.

753 4. Dambrun, M., \& Ricard, M. (2011). Self-centeredness and selflessness: A theory of self754 based psychological functioning and its consequences for happiness. Review of General $755 \quad$ Psychology, 15, 138-157.

756 5. Dambrun, M. (2016). When the dissolution of perceived body boundaries elicits happiness:

757 The effect of selflessness induced by a body scan meditation. Consciousness and 758 Cognition, 46, 89-98.

759 6. Gallagher, S. (2000). Philosophical conceptions of the self: implications for cognitive $760 \quad$ science. Trends in cognitive sciences, 4, 14-21.

761 7. Laborit, H. (1979). L'inhibition de l'action: biologie, physiologie, psychologie, sociologie.

762 Edition Masson.

763 8. Higgins, E. T. (1997). Beyond pleasure and pain. American Psychologist, 52, 1280-1300.

764 9. Wallace, B. A., \& Shapiro, S. L. (2006). Mental balance and well-being: Building bridges 765 between Buddhism and Western psychology. American Psychologist, 61, 690-701.

766 10. Brickman, P., Coates, D., \& Janoff-Bulman, R. (1978). Lottery winners and accident 767 victims: Is happiness relative? Journal of Personality and Social Psychology, 36, 917-927. 768 11. Lyubomirsky, S. (2011). Hedonic adaptation to positive and negative experiences. Oxford 769 handbook of stress, health, and coping, 200-224. 


\section{Manuscript to be reviewed}

770 12. Miller, T. Q., Smith, T. W., Turner, C. W., Guijarro, M. L., \& Hallet, A. J. (1996). A

771 meta-analytic review of research on hostility and physical health. Psychological Bulletin, $772 \quad 119,322-348$.

773 13. Dambrun, M., Ricard, M., Després, G., Drelon, E., Gibelin, E., Gibelin, M., ... \& Bray, E.

774 (2012). Measuring happiness: from fluctuating happiness to authentic-durable

775 happiness. Frontiers in psychology, doi: 10.3389/fpsyg.2012.00016

776 14. Schwartz, S. H. (1992). Universals in the content and structure of values: Theory and

777 empirical tests in 20 countries. In M. Zanna (Ed.), Advances in experimental social

778 psychology (Vol. 25) (pp. 1-65). New York: Academic Press.

779 15. Schwartz, S. H. (2003). A Proposal for Measuring Value Orientations across Nations.

$780 \quad$ Chapter 7 in the ESS Questionnaire Development Report.

$781 \quad$ http://www.europeansocialsurvey.org

782 16. Dambrun, M., \& Ricard, M. (2012). La transcendance de soi et le bonheur: une mise à

783 l'épreuve du modèle du bonheur basé sur le soi centré-décentré. Les cahiers internationaux

784 de psychologie sociale, 93, 89-102.

785 17. Leary, M. R., Tipsord, J. M., \& Tate, E. B. (2008). Allo-inclusive identity: Incorporating 786 the social and natural worlds into one's sense of self. In H. A. Wayment, \& J. J. Bauer, 787 (Eds.), Transcending self-interest: Psychological explorations of the quiet ego (pp. 137788 148). Washington DC : American Psychological Association.

789 18. Cloninger, C.R., Svrakic, D.M., \& Przybeck, T.R. (1993). A psychobiological model of 790 temperament and character. Archives of General Psychiatry, 50, 975-990.

791 19. Levenson, M. R., Jennings, P. A., Aldwin, C. M., \& Shiraishi, R. W. (2005). Self-

792 transcendence: Conceptualization and measurement. International Journal of Aging and 793 Human Development, 60, 127-143. 
794 20. Piedmont, R. L. (1999). Does spirituality represent the sixth factor of personality?

795 Spiritual transcendence and the five-factor model. Journal of Personality, 67, 985-1013.

796 21. Dovidio, J. F., \& Penner, L. A. (2001). Helping and altruism. In M. Brewer \& M.

797 Hewstone (Eds.), Blackwell international handbook of social psychology: Interpersonal

798 processes (pp. 162-195). Cambridge, MA: Blackwell.

799 22. Weinstein, N., \& Ryan, R. M. (2010). When helping helps: Autonomous motivation for 800 prosocial behavior and its influence on well-being for the helper and recipient. Journal of $801 \quad$ Personality and Social Psychology, 98, 222-244.

802 23. Fredrickson, B. L., Cohn, M. A., Coffey, K. A., Pek, J., \& Finkel, S. M. (2008). Open 803 hearts build lives: Positive emotions, induced through loving-kindness meditation, build 804 consequential personal resources. Journal of Personality and Social Psychology, 95, 10458051062.

806 24. Carson, J. W., Keefe, F. J., Lynch, T. R., Carson, K. M., Goli, V., Fras, A. M., \& Thorp, 807 S. R. (2005). Loving-Kindness Meditation for Chronic Low Back Pain. Journal of Holistic $808 \quad$ Nursing, 23, 287-304

809 25. Howell, A. J., Dopko, R. L., Passmore, H. A., \& Buro, K. (2011). Nature connectedness: $810 \quad$ Associations with well-being and mindfulness. Personality and Individual 811 Differences, 51(2), 166-171.

812 26. Sprecher, S., \& Fehr, B. (2006). Enhancement of mood and self-esteem as a result of 813 giving and receiving compassionate love. Current Research in Social Psychology, 11, $814 \quad 227-242$.

815 27. Hills, P., \& Argyle, M. (2001). Emotional stability as a major dimension of happiness. $816 \quad$ Personality and Individual Differences, 31, 1357-1364.

817 28. DeNeve, K. M., \& Cooper, H. (1998). The happy personality: A meta-analysis of 137 818 personality traits and subjective well-being. Psychological Bulletin, 124, 197-229. 
819 29. Headey, B., \& Wearing, A. (1989). Personality, life events, and subjective well-being: toward a dynamic equilibrium model. Journal of Personality and Social psychology, 57, $731-739$.

30. Lu, L. (2001). Understanding happiness: A look into the Chinese folk psychology. Journal of Happiness Studies, 2, 407-432.

824 31. Koller, J. M., \& Koller, P. J. (1998). Asian philosophies. Prentice Hall.

825 32. Yan, X. U. (2006). Self-harmony Is the Base of Structuring Psychological $826 \quad$ Harmony. Social Science of Beijing, S1.

827 33. Yaqin, C. (2008). Review on Psychological Harmony. Chongqing Social Sciences, 6, 11.

828 34. Kjell, O., Daukantaite, D., Hefferon, K., \& Sikström, S. (2015). The Harmony in Life 829 Scale Complements the Satisfaction with Life Scale: Expanding the Conceptualization of the Cognitive Component of Subjective Well-Being. Social Indicators Research, 1-27.

831 35. Preacher, K. J., \& Hayes, A. F. (2008). Asymptotic and resampling strategies for assessing and comparing indirect effects in multiple mediator models. Behavior Research Methods, 40(3), 879-891. doi:10.3758/BRM.40.3.879

834 36. Le, T. N., \& Levenson, M. R. (2005). Wisdom as self-transcendence: What's love (\& 835 individualism) got to do with it?. Journal of Research in Personality, 39, 443-457.

836 37. Dambrun, M. (2011). Des relations intergroupes au bonheur: etude de leur regulation 837 socio-psychologique. Document de synthèse de l'habilitation à diriger des recherches. $838 \quad$ Université Blaise Pascal.

839 38. Richins, M.L. (2004). The material values scale: Measurement properties and 840 development of a short form. Journal of Consumer Research, 31, 109-219.

841 39. Richins, M.L., \& Dawson, S. (1992).A consumer values orientation for materialism and 842 its measurement: Scale development and validation. Journal of Consumer Research, 19, $843 \quad 303-316$. 


\section{Manuscript to be reviewed}

844 40. Open Science Collaboration. 2015. "Estimating the Reproducibility of Psychological

$845 \quad$ Science.” Science 349: 943.

846 41. Dambrun, M. (2016). The feeling of being in harmony: Its Components and Happiness

847 Correlates. Manucript under preparation.

848 42. Plaisant, O., Courtois, R., Réveillère, C., Mendelsohn, G. A., \& John, O. P. (2010).

849 Validation par analyse factorielle du Big Five Inventory français (BFI-Fr). Analyse

850 convergente avec le NEO-PI-R. Annales Médico-Psychologiques, 168, 97-106.

851 43. Deci, E. L., \& Ryan, R. M. (2000). The"what" and "why" of goal pursuits: Human needs

852 and the self-determination of behavior. Psychological Inquiry, 11, 227-268.

853 44. Ryan, R. M., Huta, V., \& Deci, E. L. (2008). Living well: A self-determination theory

854 perspective on eudaimonia. Journal of Happiness Studies, 9, 139-170.

855 45. Ryff, C. D., \& Singer, B. (2008). Know thyself and become what you are: A eudaimonic 856 approach to psychological well-being. Journal of Happiness Studies, 9, 13-39.

857 46. Waterman, A. S. (1993). Two conceptions of happiness: Contrasts of personal

858 expressiveness (eudaimonia) and hedonic enjoyment. Journal of Personality and Social

$859 \quad$ Psychology, 64, 678-691.

860 47. Waterman, A. S., Schwart, S. J., \& Conti, R. (2008). The implications of two conceptions

861 of happiness (hedonic enjoyement and eudemonia) for the understanding of intrinsic

862 motivation. Journal of Happiness Studies, 9, 41-79.

863 48. Wayment, H. A., Wiist, B., Sullivan, B. M., \& Warren, M. A. (2011). Doing and being:

864 Mindfluness, health, and quiet ego characteristics among buddhists practitioners. Journal

865 of Happiness Studies, 12, 575-589.

866 49. Wayment, H. A., Bauer, J. J., \& Sylaska, K. (2014). The Quiet Ego Scale: Measuring the

867 Compassionate Self-Identity. Journal of Happiness Studies, 16, 999-1033. 
868 50. Leary, M. R., Adams, C. E., \& Tate, E. B. (2006). Hypo-Egoic Self-Regulation:

869 Exercising Self-Control by Diminishing the Influence of the Self. Journal of

870 personality, 74(6), 1803-1832.

871 51. Leary, M. R., \& Terry, M. L. (2012). Hypo-egoic mindsets: Antecedents and implications

872 of quieting the self. In M. R. Leary \& J. P. Tangney (Eds.),Handbook of self and identity

873 (2nd ed.). New York: Guilford.

874 52. Lo, C. S., Ho, S. M., Nicky, K. K., \& Siu, B. P. (2014). Decentering Mediates the Effect

875 of Ruminative and Experiential Self-Focus on Negative Thinking in Depression. Cognitive 876 therapy and research, 38, 389-396.

877 53. Killingsworth, M.A. and Gilbert, D.T. (2010) A wandering mind is an unhappy mind. $878 \quad$ Science. 330, 932.

879 54. Dahl, C. J., Lutz, A., \& Davidson, R. J. (2015). Reconstructing and deconstructing the 880 self: cognitive mechanisms in meditation practice. Trends in cognitive sciences, 19(9), $881 \quad 515-523$.

882 55. Fresco, D. M., Moore, M. T., van Dulmen, M. H., Segal, Z. V., Ma, S. H., Teasdale, J. D., 883 \& Williams, J. M. G. (2007). Initial psychometric properties of the experiences 884 questionnaire: validation of a self-report measure of decentering. Behavior Therapy, 38(3), $885 \quad 234-246$.

886 56. Hoge, E. A., Bui, E., Goetter, E., Robinaugh, D. J., Ojserkis, R. A., Fresco, D. M., \& 887 Simon, N. M. (2015). Change in Decentering Mediates Improvement in Anxiety in 888 Mindfulness-Based Stress Reduction for Generalized Anxiety Disorder. Cognitive Therapy 889 and Research, 39, 228-235.

890 57. Hadash, Y., Plonsker, R., Vago, D. R., \& Bernstein, A. (2016). Experiential Self891 Referential and Selfless Processing in Mindfulness and Mental Health: Conceptual Model 892 and Implicit Measurement Methodology. Psychological assessment, 28, 856-869. 
893 58. Baer, R. A., Smith, G. T., Hopkins, J., Krietemeyer, J., \& Toney, L. (2006). Using self-

894 report assessment methods to explore facets of mindfulness. Assessment, 13, 27-45.

895 59. Charles, S. T., Gatz, M., Kato, K., \& Pedersen, N. L. (2008). Physical health 25 years

896 later: the predictive ability of neuroticism. Health Psychology, 27, 369-378.

897 60. Mroczek, D. K., Spiro, A., \& Turiano, N. A. (2009). Do health behaviors explain the

898 effect of neuroticism on mortality? Longitudinal findings from the VA Normative Aging 899 Study. Journal of Research in Personality, 43(4), 653-659.

900 61. Denollet, J. (2013). Negative Affectivity. In Encyclopedia of Behavioral Medicine, (pp.

901 1304-1305). Springer New York.

902 62. Watson, D., \& Pennebaker, J. W. (1989). Health complaints, stress, and distress:

903 exploring the central role of negative affectivity. Psychological review, 96, 234-254.

904 63. Kashdan, T. B., \& Breen, W. E. (2007). Materialism and diminished well-being:

905 Experiential avoidance as a mediating mechanism. Journal of Social and Clinical

906 Psychology, 26(5), 521-539.

907 64. Ip, P. K. (2014). Harmony as Happiness? Social Harmony in Two Chinese

908 Societies. Social indicators research, 117(3), 719-741.

909 65. Uchida, Y., \& Kitayama, S. (2009). Happiness and unhappiness in east and west: themes $910 \quad$ and variations. Emotion, 9(4), 441.

911 66. Carlo, G., Mestre, M. V., McGinley, M. M., Samper, P., Tur, A., \& Sandman, D. (2012).

912 The interplay of emotional instability, empathy, and coping on prosocial and aggressive

913 behaviors. Personality and Individual Differences, 53(5), 675-680.

914 67. McCrae RR, Costa PT. The stability of personality: Observation and evaluations. Current 915 Directions in Psychological Science, 3, 173-175. 


\section{Manuscript to be reviewed}

916 68. Roberts, B. W., Walton, K. E., \& Viechtbauer, W. (2006). Patterns of mean-level change

917 in personality traits across the life course: a meta-analysis of longitudinal studies.

$918 \quad$ Psychological bulletin, 132, 1-25.

919 69. Specht, J., Egloff, B., \& Schmukle, S. C. (2011). Stability and change of personality

920 across the life course: the impact of age and major life events on mean-level and rank-

921 order stability of the Big Five. Journal of personality and social psychology, 101, 862-

922882.

923 70. Soto, C. J. (2015). Is happiness good for your personality? Concurrent and prospective

924 relations of the big five with subjective well-being. Journal of personality, 83, 45-55.

925 71. Kahneman, D. (1999). Objective happiness. In D. Kahneman, E. Diener, N. Schwarz, D.

926 Kahneman, E. Diener, N. Schwarz (Eds.), Well-being: The foundations of hedonic

927 psychology (pp. 3-25). New York, NY US: Russell Sage Foundation.

928 72. Steger, M. F., Kashdan, T. B., \& Oishi, S. (2008). Being good by doing good:

929 Eudaimonic activity and daily well-being correlates, mediators, and temporal relations.

$930 \quad$ Journal of Research in Personality, 42, 22-42.

931

932

933

934

935

936

937

938

939

940 
941 Table 1. Sample Characteristics

\begin{tabular}{lcc}
\hline \multicolumn{1}{c}{ Characteristics } & Study 1 & Study 2 \\
\hline$N$ & 243 & 304 \\
& & \\
Population & Regional community & National community \\
& & \\
Age mean in years $(S D)$ & $40.5(17.3)$ & $40.8(16.5)$ \\
Age range in years & $18-87$ & $17-86$ \\
& 53.0 & 62.2 \\
Female (\%) & 33.5 & 37.5 \\
Religious believer $(\%)$ & $2.9(.52)$ & $2.9(.42)$ \\
Socio Economic Status $(S D)$ & $2.9(1.0)$ & $2.6(2.1)$ \\
Education $(S D)$ & & \\
& & \\
\hline
\end{tabular}

942 Note: SES was coded from 1 (extremely low SES) to 5 (extremely high SES). Similarly, 943 education was coded from 1 (extremely low education) to 5 (extremely high education). 
959 Table 2. Relationships between various variables (study $1 ; n=243$ )

\begin{tabular}{|c|c|c|c|c|c|c|c|c|}
\hline & $M$ & $S D$ & 1 & 2 & 3 & 4 & 5 & 6 \\
\hline $\begin{array}{l}\text { 1. Self- } \\
\text { Transcendence }\end{array}$ & 4.42 & .89 & - & & & & & \\
\hline $\begin{array}{l}\text { 2. Connectedness } \\
\text { (Other) }\end{array}$ & 3.87 & .79 & $.31 * * *$ & - & & & & \\
\hline $\begin{array}{l}\text { 3. Connectedness } \\
\text { (Nature) }\end{array}$ & 2.64 & 1.15 & $.31 * * *$ & $.54 * * *$ & - & & & \\
\hline 4. Egocentrism & 3.21 & .94 & $-.29 * * *$ & $-.16^{*}$ & -.08 & - & & \\
\hline 5. Materialism & 3.56 & .99 & $-.16^{*}$ & -.07 & -.04 & $.38 * * *$ & - & \\
\hline $\begin{array}{l}\text { 6. Subjective } \\
\text { Fluctuating } \\
\text { Happiness (SFHS) }\end{array}$ & 3.95 & 1.30 & -.07 & -.04 & .07 & $.40 * * *$ & $.21 * * *$ & - \\
\hline $\begin{array}{l}\text { 7. Subjective } \\
\text { Authentic-Durable } \\
\text { Happiness (SA- } \\
\text { DHS) }\end{array}$ & 4.24 & 1.02 & $.34 * * *$ & $.23 * * *$ & .05 & $-.20 * *$ & -.09 & $-.50 * * *$ \\
\hline
\end{tabular}

960 Note: $* * * p<.001 ; * * p<.01 ; * p<.05$

961

962

963

964

965

966

967

968

969

970

971

972

973

974

975 
976 Table 3. Relationships between Self-centeredness/Selflessness and Happiness (study 1; $n=$ $977 \quad 243)$

Self-centeredness $\quad$ Selflessness

\begin{tabular}{lcccc}
\hline & $\beta$ & $\begin{array}{c}\text { Partial } \beta \\
\text { (controllingfor } \\
\text { selflessness) }\end{array}$ & $\beta$ & $\begin{array}{c}\text { Partial } \beta \\
\text { (controlling for } \\
\text { self-centeredness) }\end{array}$ \\
\hline $\begin{array}{l}\text { Subjective Fluctuating } \\
\text { Happiness (SFHS) }\end{array}$ & $.36^{* * *}$ & $.37 * * *$ & -.07 & .02 \\
$\begin{array}{l}\text { Subjective Authentic- } \\
\begin{array}{l}\text { Durable Happiness (SA- } \\
\text { DHS) }\end{array}\end{array}$ & $-.17^{* *}$ & -.08 & $.36^{* * *}$ & $.33^{* * *}$ \\
\hline Note: $* * * p<.001 ; * * p<.01$. & & & \\
\hline
\end{tabular}

978 Note: $* * * p<.001 ; * * p<.01$.

979

980

981

982

983

984

985

986

987

988

989

990

991

992

993

994

995 
996 Table 4. Relationships between various variables (study $2 ; n=304$ )

\begin{tabular}{|c|c|c|c|c|c|c|c|c|c|c|c|}
\hline & $M$ & $S D$ & 1 & 2 & 3 & 4 & 5 & 6 & 7 & 8 & 9 \\
\hline 1. Self-Transcendence & 4.49 & .99 & - & & & & & & & & \\
\hline 2. Connectedness (Other) & 4.10 & .93 & $.37 * * *$ & - & & & & & & & \\
\hline 3. Connectedness (Nature) & 3.05 & 1.36 & $.25 * * *$ & $.55 * * *$ & - & & & & & & \\
\hline 4. Egocentrism & 2.93 & .95 & -.03 & -.05 & -.03 & - & & & & & \\
\hline 5. Materialism & 3.39 & 1.00 & $-.14^{*}$ & .03 & -.05 & $.26 * * *$ & - & & & & \\
\hline $\begin{array}{l}\text { 6. Subjective Fluctuating } \\
\text { Happiness (SFHS) }\end{array}$ & 3.68 & 1.30 & -.02 & .00 & .04 & $.17 * *$ & $.17 * *$ & - & & & \\
\hline Mediating variables & & & & & & & & & & & \\
\hline 8. Afflictive affects & 3.04 & .92 & -.02 & .04 & .05 & $.44 * * *$ & $.20 * * *$ & $.36 * * *$ & -.05 & - & \\
\hline $\begin{array}{l}\text { 9. Feeling of being in } \\
\text { harmony }\end{array}$ & 4.31 & .78 & $.39 * * *$ & $.42 * * *$ & $.47 * * *$ & -.06 & $-.18 * *$ & $-.23 * * *$ & $.59 * * *$ & .00 & - \\
\hline 10. Emotional stability & 3.07 & .86 & $.34 * * *$ & $.21 * * *$ & .09 & -.08 & $-.12 *$ & $-.59 * * *$ & $.55 * * *$ & $-.29 * * *$ & $.41 * * *$ \\
\hline
\end{tabular}


1032 Table 5. Relationships between Self-centeredness/Selflessness and Happiness (study 2; $n=$

1033 304)

\begin{tabular}{|c|c|c|c|c|}
\hline & \multicolumn{2}{|c|}{ Self-centeredness } & \multicolumn{2}{|c|}{ Selflessness } \\
\hline & $\beta$ & $\begin{array}{c}\text { Partial } \beta \\
\text { (controlling for } \\
\text { selflessness) }\end{array}$ & $\beta$ & $\begin{array}{c}\text { Partial } \beta \\
\text { (controlling for } \\
\text { self-centeredness) }\end{array}$ \\
\hline $\begin{array}{l}\text { Subjective Fluctuating } \\
\text { Happiness (SFHS) }\end{array}$ & $22 * * *$ & $.22 * * *$ & -.02 & .00 \\
\hline $\begin{array}{l}\text { Subjective Authentic- } \\
\text { Durable Happiness (SA- } \\
\text { DHS) }\end{array}$ & -.07 & -.03 & $.48 * * *$ & $.48 * * *$ \\
\hline
\end{tabular}

1034 Note: $* * * p<.001 ; * * p<.01$.

1035

1036

1037

1038

1039

1040

1041

1042

1043

1044

1045

1046

1047

1048

1049

1050

1051

1052

1053

1054

1055

1056

1057

1058

1059

1060

1061

1062

1063

1064

1065

1066 
1067 Figure $1 A$ and $1 B$. Mediation Model: Afflictive Affects as a Mediator of the Relationship

1068 between Self-centeredness and Subjective Fluctuating Happiness (study 2)

1069

1070

A

1071

1072

1073

1074

1075

1076

1077

1078

1079

1080

1081

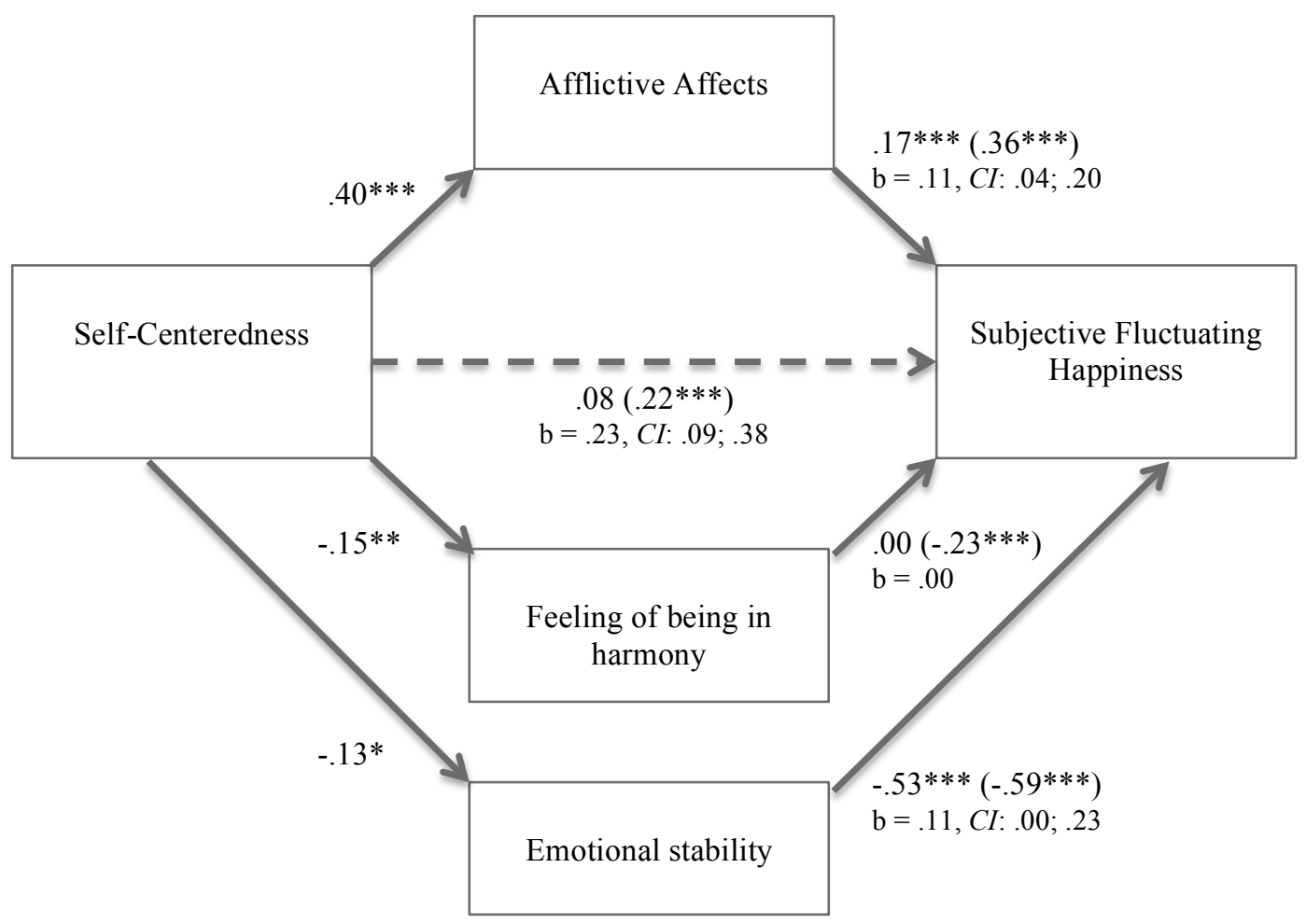

1082

1083

1084

B

1085

1086

1087

1088

1089

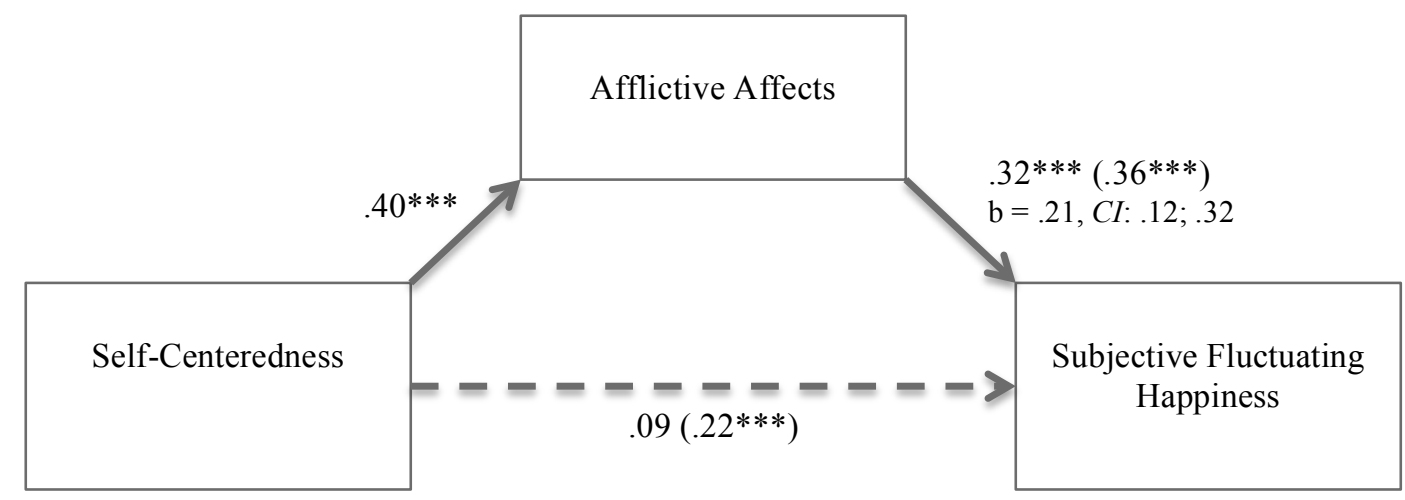

1090

1091

1092 
1095 Figure 2. Mediation Model: Feeling of Harmony and Emotional Stability as Two Independent

1096 Mediators of the Relationship between Selflessness and Subjective Authentic-Durable

1097 Happiness (study 2)

1098

1099

1100

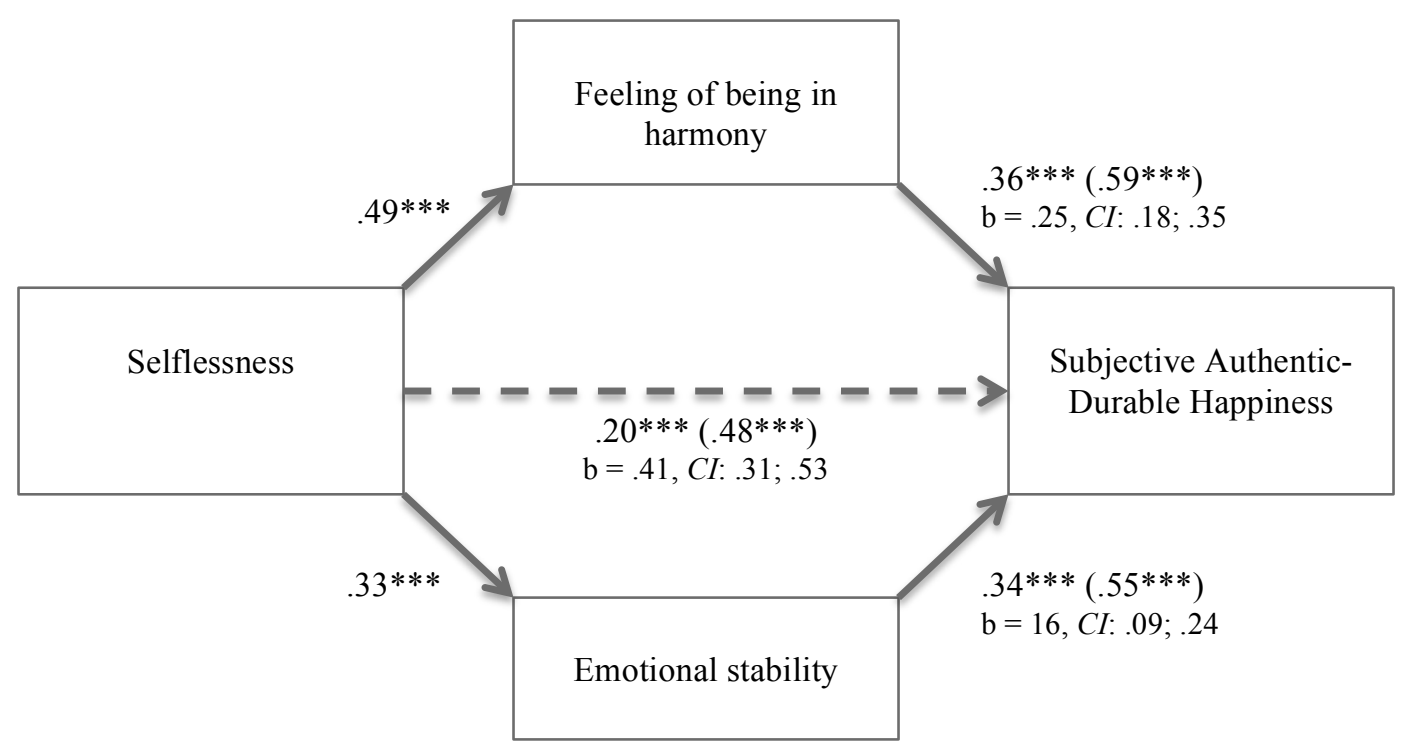

